\title{
SYPHILIS IN PREGNANCY
}

BY

\section{CHAIM BERLIN and CLARA MEYROVITZ}

From the Dermatological Department of the Municipal Hospital, Hadassah, Tel-Aviv, Israel

In preventive medicine, prenatal care plays an important role, and one of its chief aims is to care for syphilis in expectant mothers. The Municipality of Tel-Aviv has established a network of prenatal clinics, where roughly 80 per cent. of the pregnant women, most of whom come from the lowest section of the city, and are largely new immigrants, are regularly supervised.

In 1944, a routine serologic blood examination with the Rappaport test (Rappaport and Eichhorn, $1943,1944,1946,1951$ ) was introduced; 37,540 such tests were performed between August, 1944, and August, 1952, and 153 showed a positive or doubtful reaction. These women and those with some history of a syphilitic infection, were referred to our Department for further study.

The Wassermann, Kahn, and Meinicke tests were then performed in the Serological Laboratory and repeated as necessary, because the reactions were often not identical. Such differences as ,++++ \pm , or complete negative were not rare. All was done to confirm the diagnosis. Each woman was interviewed carefully, but the history was frequently unreliable. Physical examination took place in the Internal Medicine Clinic, and when indicated, in the Neurological Clinic. The husband was almost always examined serologically and clinically, and also the woman's parents if congenital syphilis was suspected, and attendant physicians were questioned. Several weeks were sometimes taken to assemble the necessary information. On the basis of such data-not always reliable and available - we had to draw a conclusion as to the diagnosis, stage of the disease, and indication for treatment or re-treatment. Especially difficult to interpret were the rather numerous cases, clinically negative and without history, where the "positive blood" was the only indication of a syphilitic infection. They present a diagnostic and therapeutic problem, particularly in pregnancy, where the risk is doubled and there is no time to wait. A disastrous outcome at the beginning of our campaign-still in the pre-penicillin era-taught us to be cautious and to act on the dictum " if in doubt, treat".
A primigravida with a negative history and clinically normal, showed in repeated examinations a $1+$ Rappaport and $1+\mathrm{Kahn}$. The husband was clinically and serologically normal. It was decided not to treat, and she delivered a dead infant showing signs of syphilis.

\section{Material}

Altogether 111 women were selected for specific treatment, which was administered in 127 pregnancies ; sixteen women received additional treatment in their subsequent pregnancies. Their ages ranged from 16 to 47 and they were in various stages of gestation. The therapy rarely began in the first trimester, but often in the second, and even in the third. Thirty women were primiparae, and others had had two or more pregnancies.

\section{Stage of the Disease}

Our material was of such a character that the stage of syphilis could not easily be determined (see Table).

TABLE

STAGE OF SYPHILIS WHEN THERAPY WAS STARTED

\begin{tabular}{|c|c|c|c|c|c|}
\hline \multirow{2}{*}{ Early Syphilis } & & \multirow{2}{*}{$\ldots$} & \multicolumn{2}{|c|}{ Symptomatic } & 12 \\
\hline & & & \multicolumn{2}{|c|}{ Latent } & 14 \\
\hline \multirow{2}{*}{ Late Syphilis } & \multirow{2}{*}{. } & \multirow{2}{*}{$\cdots$} & \multicolumn{2}{|c|}{ Symptomatic } & 20 \\
\hline & & & \multicolumn{2}{|c|}{ Latent } & 37 \\
\hline \multicolumn{3}{|c|}{$\begin{array}{l}\text { Congenital Syphilis } \\
\text { Questionable Syphilis . } \\
\text { Undetermined .. }\end{array}$} & $\begin{array}{l}\cdots \\
\cdots \\
\cdots\end{array}$ & $\begin{array}{l}\cdots \\
\cdots \\
\cdots\end{array}$ & $\begin{array}{r}8 \\
9 \\
11\end{array}$ \\
\hline Total & $\ldots$ & . & $\cdots$ & $\ldots$ & 111 \\
\hline
\end{tabular}

There was no case of primary syphilis. Early latent syphilis was assumed, when according to reliable history given by the patient or attendant physician, the disease had lasted not more than 4 years. In eleven instances however, the duration of the asymptomatic syphilis could not be determined accurately. Lues congenita was diagnosed by certain symptoms or by examination of the parents. In nine cases diagnosis was uncertain and treatment was given because of some degree of sero-positivity. 
In 45 cases the patients were unaware of their infection and consequently had not received previous specific treatment; 42 had received some type of syphilotherapy, but its amount could not be ascertained. In 39 pregnancies it was decided to treat or re-treat, because of the early stage of the disease or the persistent sero-positivity of the serological tests.

\section{Re-Treatment}

The question of the re-treatment of pregnant women, who have previously received anti-syphilitic therapy, has again arisen in the literature after experience with penicillin. Optimistic views were expressed by several authors (Goodwin and Farber, 1948 ; Ingraham and others 1948 ; Wammock and others, 1950 ; Shaffer and Courville, 1951), who proposed the withholding of additional therapy in pregnancy when penicillin had previously been given. Tucker (1949a) permitted to go untreated in pregnancy 88 women who had previously received penicillin in doses of 3 million units or more for early syphilis, and unsatisfactory results were no more numerous than in a non-syphilitic group. The author demands, however, that the women should be examined clinically and serologically at monthly intervals during pregnancy. We were more cautious and preferred to re-treat early syphilis in pregnancy. It was sometimes easier to administer to an uncooperative woman a course of penicillin than to compel her to come to the clinic for monthly examinations. Likewise it became our routine practice to give penicillin to an expectant mother who was known to have had syphilis, irrespective of the stage of the disease and of the amount of previous therapy with arsenic and bismuth. Only women with asymptomatic late syphilis were allowed to go untreated through pregnancy, even when the blood was not negative, provided they had previously received apparently adequate treatment (including at least one course of penicillin).

\section{Type of Treatment}

In 1944, encouraging reports of the results obtained with penicillin in syphilis began to appear in the literature. We felt, however, that it was too early to abandon the well-tried methods of therapy, and 25 patients were treated with metal chemotherapy. Our routine dose was ten weekly injections of $0.45 \mathrm{~g}$. arsphenamine and eighteen to twenty bi-weekly intramuscular injections of bismuth subsalicylate in oil, $0 \cdot 15 \mathrm{~g}$. per dose. Most women completed or nearly completed the full scheme of treatment which, by the way, was well tolerated. Twelve received arsenicals and bismuth in combination with penicillin. Since 1948 we have used penicillin alone in amounts ranging from 4,000,000 to $6,000,000$ units. We chose the higher dosage because of our aim not only to protect the foetus but also to treat adequately the maternal syphilis.

Penicillin 80,000 units every 3 hours, was given to 56 women, who were hospitalized for this purpose for 8 to 10 days. When penicillin in absorption-delaying vehicles became available, this was used on an out-patient basis. Our present routine schedule is ten daily injections of 600,000 units procaine penicillin $G$ in oil with 2 per cent. aluminium monostearate (PAM).

No serious side-effects were noted from penicillin with the exception of one case of a reaction resembling serum-sickness.

A woman who, 2 days before, had completed a course of aqueous penicillin in the hospital, was re-admitted with giant-sized urticarial lesions, angioneurotic oedema of the face, swelling of several joints and a temperature of $39.5^{\circ} \mathrm{C}$. Recovery occurred after 10 days, and she subsequently delivered a full-term healthy baby.

\section{Results}

Most of the treated women were delivered in hospital, and we were able to examine almost every infant and also the cord blood. There were fifteen unfavourable results among 127 pregnancies, seven of which were not attributed to syphilis. Of the remaining eight, four should be classified as possibly and four as probably due to syphilis. Of these eight failures, four had been treated with metal preparations, one with metal and penicillin, and three with penicillin alone. The failures occurred only in patients with early symptomatic or latent syphilis, in whom no apparent relapse or re-infection could be noted. A woman with congenital syphilis delivered a dead infant, weighing $1,250 \mathrm{~g}$., but autopsy showed no evidence of a syphilitic infection.

\section{Case Reports}

Case 1, a woman aged 23, was referred to our clinic in the sixth month of her first pregnancy. She and her husband had acquired syphilis 2 years before and had received no specific treatment. Blood tests were ++++ . The woman was given two injections of bismuth and one of neoarsphenamine. She delivered a macerated syphilitic infant which died after several hours.

Comment.-This is not a true case of "treatment failure." The failure could have been prevented if the therapy had been started earlier. Soloway (1945), analysing the results obtained in several hundred pregnant women treated with arsenicals and bismuth, found 94.3 per cent. of non-syphilitic children when therapy was started before the end of the fourth month of pregnancy, and 50.6 per cent. of normal children when treatment was started after the fifth month. These 
figures are bettered by penicillin, which readily permeates the placenta and cures the infected foetus (Cole and others, 1946 ; Tucker, 1949b ; Ingraham and Beerman, 1950 ; Bundesen and others, 1950).

Case 2, a woman aged 21, was referred to our clinic in 1944 in the fifth month of her second pregnancy; $2 \frac{1}{2}$ years previously she had been seen with a florid secondary syphilis, complicated by a pregnancy. She had been uncooperative, had received several injections of bismuth and neoarsphenamine only, and had had a stillbirth. This time she completed a full course of metal chemotherapy and delivered a full-term boy with no signs of syphilis. An $x$ ray of the long bones was unfortunately not made but the blood test was strongly positive. He received stovarsol and bismuth, was followed up for several years, and made normal progress.

Comment.-A positive reaction in the infant is often caused by a transfer of the mother's reagin and is by no means diagnostic of syphilis unless the sero-positivity persists after several months. Shaffer and Courville (1951) followed up 100 infants with positive serological tests, and 92 of them were subsequently proved to be non-syphilitic. Nevertheless, we decided to treat this infant because of the mother's history. Her treatment was only started in the second half of her pregnancy, and the degree of the child's sero-positivity exceeded that of the mother. The case was classified as possibly related to syphilis.

Case 3, a woman aged 23, with early asymptomatic syphilis, was given a full course of neoarsphenamine and bismuth in the sixth month of her first pregnancy. She delivered a normal infant with a negative blood test, but 2 months later the child developed papules on the soles of the feet, enlargement of the liver and spleen, and a positive blood test.

Comment.-A negative reaction in a newborn infant does not necessarily imply that it has not been infected. The children born of syphilitic mothers should be followed up for at least 6 months.

Case 4, a primipara aged 26, in the fourth month of pregnancy, was first seen with muco-cutaneous lesions typical of secondary syphilis. She was treated in the Government Hospital, and received 3.7 million units aqueous penicillin in 8 days. We added a course of neoarsphenamine and bismuth. Her infant, weighing 900 g., lived for only 14 hours.

Comment.-This case indicates that there is no 100 per cent. safety with penicillin, even combined with metal therapy.

After delivery, we continued to treat the mothers who failed to obtain a healthy child. One woman who had a stillbirth after penicillin delivered a healthy infant in a subsequent pregnancy after an additional course of penicillin. Mothers who gave birth to non-syphilitic children were also sometimes re-treated. The delivery of a healthy child does not necessarily mean that the maternal syphilis is cured.
The children were followed-up for at least 6 months in the Paediatric Clinic. The follow-up of the mothers before and after delivery was made possible by the valuable help of the Prenatal, Obstetrical, and Post-natal Clinics.

\section{Summary}

During the eight years, 1944-52, routine serologic blood examination of 37,540 pregnant women revealed 153 positive or doubtful reactions.

Specific treatment was administered to 111 expectant mothers in 127 pregnancies : 26 women had early symptomatic or latent syphilis (of less than 4 years' duration); 57 had late symptomatic or latent syphilis; eight had congenital syphilis ; in eleven the stage could not be ascertained; in nine there was only questionable evidence of syphilis.

In 25 cases the patients received arsphenamine and bismuth therapy, in twelve metal chemotherapy concurrently with penicillin, and in eighty penicillin alone.

Aqueous penicillin 3-hourly, totalling 4.8 million units, was given to 56 patients in hospital, and procaine penicillin 600,000 units daily for 10 days was given to 52 outpatients.

In most cases syphilotherapy was started in the second half of the pregnancy.

There were eight treatment failures, four possibly and four probably due to syphilis. They all occurred in patients with early syphilis, after treatment with metal chemotherapy (4), penicillin (3), and chemotherapy with penicillin (1).

In addition to the important advantages of convenience of application, almost complete lack of toxicity, and brevity of treatment, penicillin given to an expectant mother has superior therapeutic effects and offers greater safety for the child.

\section{REFERENCES}

Bundesen, H. N., Rodriquez, J., Aron, H. C. S., and Korman, B. F. (1950). Arch. Derm. Syph. (Chicago), 62, 230.

Cole, H. N., Ayres, S., Barr, J. H., Genatios, T., Held, B., Murphy, W. W., Printz, D. R., and Strauch, J. (1946). Ibid., 54, 255.

Cross, J. B., McCain, J. R., and Heyman, A. (1949). Amer. J. Obstet. Gynec., 57, 461.

Goodwin, M. S., and Farber, M. S. (1948). Amer. J. Syph., 32, 409. Ingraham, N. R., and Beerman, H. (1950). Amer. J. med. Sci., 219, 433.

—, Rose, E. K., Stokes, J. H., and Beerman, H. (1948). Amer. J. Obstet. Gynec., 56, 340.

Rappaport, F., and Eichhorn, F. (1943). Lancet, 1, 426.

- - (1944). Ibid, 2, 599.

_-, —_(1946). Arch. Derm. Syph. (Chicago), 54, 345. (1951). Acta med. orient. (Tel-Aviv), 10, 200.

Shaffer, L. W., and Courville, C. J. (1951). Arch. Derm. Syph. (Chicago), 63, 91.

Soloway, H. M. (1945). J. Amer. med. Ass., 129, 500.

Tucker, H. A. (1949a). Amer. J. med. Sci., 217, 157.

--(1949b). Amer. J. Syph., 33, 1.

Wammock, v. S., Carrozzino, O. M., Ingraham, N. R., and Clair, N. E. (1950). Amer. J. Obstet. Gynec., 59, 806. 